\title{
Knowledge \&Practices of Exclusive Breast Feeding in Fayoum, Egypt
}

\author{
Safaa Khamis Hassan* and Wafaa Yousif Abdelwahed* \\ *Public Health and Community Medicine Department Fayoum University
}

\begin{abstract}
Background Breastfeeding is an important public health strategy for improving infant and child morbidity and mortality, The WHO recommends that for the first six months of life, infants should be exclusively breastfed. This study aimed at assessing exclusive breastfeeding EBF knowledge, and practice among lactating mothers attending Benisaleh Family Health Unit having infant aged from 2-6 moths. Methods: A cross-sectional study using structured questionnaire was conducted among mothers having infant aged from 2-6 months attending Bensaleh FHU for immunization practices through period from July to September 2013. Results: Out of 400 mothers interviewed; exclusive breast feeding was reported among $50(12.5 \%)$. The mean total knowledge score of participants was $10.22 \pm 2.9 \&$ ranged from 4 to 22 out of 27 knowledge questions. The mean knowledge score was significantly higher in mothers, with higher education, working mothers and those who received knowledge from media \& combined source than those with lower education, not working and who received knowledge from PHC workers. The significant predictors for exclusive breastfeeding practice among participants were; male sex, early breastfeeding initiation after delivery, and good knowledge with odds ratios of 3.02, 13.2 and 7.9 respectively

Conclusion and Recommendation: There was a lack of knowledge and correct feeding practice regarding EBF. Urban and educated mothers have good knowledge. Counseling for mothers on EBF needs to be improved and health care workers need to be better trained to provide counseling services during antenatal care visits.

Key Words EBF, knowledge, practices, lactating mothers, breast milk
\end{abstract}

\section{Introduction}

Exclusive breastfeeding (EBF) is a simple, cheap and cost effective intervention in reducing child mortality and morbidity in low income countries $(1,2)$. According to the World Health Organization (WHO), breast milk has the complete nutritional requirements that a baby needs for healthy development. Furthermore, it is safe and contains antibodies that help protect infants and boost immunity. Consequently, breastfeeding contributes to reduced infant morbidity and mortality due to diarrhea, respiratory or ear infections and other infectious diseases. For the mother, breastfeeding is economical; breast milk is always available, clean and at the right temperature. Breastfeeding also delays the return of fertility and reduces the risk of developing breast and ovarian cancers. (3) The World Health Organization (WHO) recommends exclusive breastfeeding for the first six months of life and continued breastfeeding up to two years of age or beyond. Exclusive breastfeeding is defined as feeding the infant only breast 
milk, with no supplemental liquids or solids except for liquid medicine and vitamin/mineral supplements (4) Globally, Not more than $35 \%$ of infants worldwide are exclusively breastfed during their first four months of life $(5,6,7)$. the prevalence of exclusive breast feeding in developing countries varied. Madagascar, (70\%), Zambia, (74\%), Ghana, (79\%) and Bolivia (65\%). Amhara Region, (81\%), Oromia Region, $(62 \%)$ and South Nations and Nationalities Peoples Region (64\%). But this finding is higher than the findings in Lebanon (10\%), Bangladesh (36\%) and the national exclusive breastfeeding prevalence in Ethiopia (49\%). $(6,12)$ Promotion of exclusive breastfeeding is the single most cost-effective intervention to reduce infant mortality in developing countries (8-11). It is estimated that sub-optimal breastfeeding, especially non-exclusive breastfeeding in the first six months of life, results in 1.4 million deaths and $10 \%$ of diseases in under-fives. Non-exclusive breastfeeding also has long term impact, including poor school performance, reduced productivity, and impaired intellectual and social development. It can also increase the risk of dying due to diarrhea and pneumonia among 0-5 month old infants by more than two-fold $(9,10)$. This study aimed at evaluating knowledge and practices of lactating mothers toward EBF and identifying factors affecting them.

\section{Subjects and methods}

This study is a descriptive crosssectional design aiming to assess exclusive breast feeding knowledge, and practice among lactating mothers attending FHU.

\section{Study setting and population}

The study was conducted in The rural Family medicine Health Unit (FHU) in Beni-Saleh, Fayoum district among lactating mothers who came to well baby \& immunization clinic having a child from 2 to 6 months. Based on the last census Egypt; 2006, this family medicine health unit serves about 24.000 people. The expected number of married women in the child bearing years near 4000 women that is the target population.

To select study participants a purposive sample technique was used. The sample size was determined using single population proportion equation _with the following considerations: $95 \%$ level of confidence $(Z=1.96) ; 5 \%$ margin of error and $50.0 \%$ percent of participants with good knowledge. Thus minimum size required was 384 . the total size taken in this study was 400 .

\section{Data collection}

Social workers in PHC called Raedat Refeats were trained to interview these mothers using predesigned and pretested structured questionnaire covered the following items (Sociodemographic characteristics, knowledge \& practices towards BF).

\section{Ethical approval}

The study received the approval of the Research and Ethics Committee of Faculty of Medicine, Fayoum University. Informed oral consents were obtained from all participants in the study.

\section{Statistical analysis}

Data were coded, validated and analyzed using SPSS version 16. Descriptive statistical analyses were performed

At the stage of data analysis a scoring system was used for knowledge 
questions. The correct answer was given a score 1 and the wrong answer and (don't know) were given score 0 . Knowledge score was calculated for general knowledge questions covering 7 items and benefits of BF for baby questions 11 items, benefits of $\mathrm{BF}$ to mothers questions 6 items and overcoming BF problems 3 items. The total knowledge score was calculated by summation of the total items covering 27 items. A cut-off point was determined on the basis of the median value of the total knowledge score (10) participants at or above the median value were classified as having good knowledge, whereas those having a total knowledge score less than the median value were classified as having poor knowledge. $t$ test and ANOVA test were used to compare quantitative variables between groups while chi-square was used to compare qualitative data. Logistic regression analysis was done to test for significant predictors for good knowledge and exclusive breastfeeding, $P$ value less than 0.05 was considered statistically significant.

\section{Results}

Table 1: The data of the study was collected from 400 mothers having infants aged from 2 to 6 months; nearly half $49.5 \%$ of infants at the age of 6 months. The males represented $48.3 \%$ of infants. The mean age of participants was $28.06 \pm 5.8$, the majority were married (96\%. Employed mothers represented (75.0\%). Nearly one fourth of participants $(23.5 \%)$ had more than 3 children

Table 2: revealed that $59 \%$ of mothers knew the best time to initiate BF after delivery while most of mothers $79 \%$ knew that times to BF day and night is on demand, on the other hand $63 \%$ and $25 \%$ respectively of mothers knew that they shouldn't give a baby Artificial Formula or fluids in her/his first six months . Nearly half (49\%) of mothers correctly knew the age of EBF. Only $23.5 \%$ of mothers mentioned the importance of cleaning breast before lactation.

Figure 1: Most of mothers knew the importance of BF to the baby regarding giving immunity against diseases by (95.5\%), helping in relieve physiologic jaundice by (84.5) and Provocative (speeds the passage of meconium) by (73.0). other advantages of BF to baby mentioned in table 3 were poorly known to participants.

Figure 2: Regarding advantages of $\mathrm{BF}$ to mother; few percentages of mothers correctly identified them except the item mentioned quick in valuation of uterus that was identified by $85 \%$ of participants .

Table 3: Distribution of mothers by their knowledge about some BF problems showed wrong concepts in the mind of mothers when dealing with these problems; i.e. the largest percentage of participants mentioned Give the baby AF by bottle \& Give the baby fluids (tea, herbals) by bottle in the management of scanty milk. Breast engorgement management by stopping breast feeding and massaging the breast was mentioned by $28.5 \%$ and $15.5 \%$ of participants.

Table 4: showed the mean knowledge scores of different subgroups of the study group. The mean knowledge score of working participants was significantly higher than not working $(p=0.000)$. Also the mean scores were higher with education as secondary and higher than those with lower education $(\mathrm{p}=0.019)$. Regarding source of 
information about $\mathrm{BF}$; the mean score of mothers received information from media and combined source was higher than those who received counseling from health workers

\section{Practices}

Table 5 revealed that $43 \%$ of mothers practiced BF within the first hour after labour. The majority $(65.0 \%)$ never cleaned their breast before feeding. Regarding feeding pattern most participants $(85.5 \%)$ uses both sides a time. $31 \%$ of mothers gave artificial formula while $85 \%$ of mothers gave fluids. Only $19 \%$ of mothers practiced $\mathrm{BF}$ in a single sitting for 20-30 minutes. The majority $(75 \%)$ of participants introduced complementary food through the $1^{\text {st }}$ six months, the largest percentage introduced (69.3\%) Food at age of 3-4 months.

The percent of participants who exclusively breastfed their infants with no fluids, artificial and complementary food was $12.5 \%$.

Table 6 showed that there was significant association between the practice of EBF and male gender of then Becky sex $(p<0.03)$, age of infant ( $p$ 0.006) where percent of infants aged 2 months received significantly higher rate of exclusive than older exclusive infants. Also there was significant association between exclusive breast feeding, early initiation of breastfeeding after delivery and absence of breast feeding difficulties $(\mathrm{p}>0.10)$.

Table 7 showed the significant predictors for good knowledge by logistic regression analysis. Working of mothers and receiving $\mathrm{BF}$ knowledge through media and combined were the significant predictors for good knowledge with odds ratios of $8.24,3.07$ respectively
Table 8 showed the significant predictors for exclusive breastfeeding by logistic regression analysis; male sex of the Baby early breastfeeding initiation after delivery, and good knowledge were the significant predictors associated with higher chance for exclusive breastfeeding with odds ratios of 3.02 , 13.2 and 7.9 respectively.

\section{Discussion}

Egypt is one of the developing countries in which we need to support correct feeding practices. Exclusive breastfeeding is a safe, economical, and emotionally satisfying means of feeding babies. The present study aimed to identify knowledge, and practice among mothers regarding breast feeding.

The data of the study was collected from 400 mothers having infant aged from 26 months and attended to primary health unit for immunization of their children. More than half of mothers (59\%) had an idea on starting breast feeding within 1 hour (table 2 ) but in practice only $43.5 \%$ of mothers started the breast feeding within 1 hour (table 5) this was lower than the findings of the $2008 \mathrm{EDHS}^{(13)}$, which showed that $56 \%$ of the mothers breastfed their infants within the first hour and this was because they were given some type of liquid until the mother's breast milk flowed freely . While Chaudhary et al ${ }^{(14)}$ reported only $10 \%$ mothers knew that they had to start breast feeding within $1 / 2-1 \mathrm{hr}$ of birth and in practice $41.5 \%$ mothers started breast feeding within $1 / 2-1$ hr of birth. WHO recommends that appropriate $\mathrm{BF}$ practices include on demand and not less than 10 times day and night ${ }^{(25)}$. In our finding this was well known by the majority of mothers $(93 \%)$ on demand (table2) but in practice only $75 \%$ 
mothers were giving BF on demand (table 5). This was similar to the value reported from studies conducted in Egypt, $80.3 \%$ of the mothers reported breastfeeding on demand ${ }^{(23)}$, while in Sweden, most of the mothers reported that they breastfed on demand ${ }^{(24)}$. Breast feeding at one side until whole breast is emptied out should be the practice among mothers. This way allows baby getting the hind milk, which is required for brain development. In our finding, only $7.5 \%$ mothers knew that they had to breast feed on one side until whole breast was emptied (table 2) but $14.5 \%$ were practicing (table 5). This was similar to Chaudhary et $\mathrm{al}^{(14)}$ who reported that, only $5 \%$ of mothers knew they had to breastfeed on one side until whole breast was emptied but $15 \%$ were practicing.

Breastfeeding is an important public health strategy for improving infant and child morbidity and mortality, improving maternal morbidity ${ }^{(26)}$ of in our finding, lower percentage of mothers knew the protective role of $\mathrm{BF}$ against different infections for the baby or brain and GIT development (figure 1) while the majority of mothers don't know the protective effect against cancer and about half of mothers knew protective effect in delaying conception (figure 2). This reflect lack of knowledge regarding the benefits of BF especially to mothers. This was similar to Abul-Fadl et al ${ }^{(27)}$ who reported that lower percentage of mothers in upper Egypt knows about the protective effects of breastfeeding, particularly against breast cancer and the lowest level of knowledge was about the potential contraceptive effect of exclusive breastfeeding. Through Promotion Program conducted in Gaza by Abu Hassan \& Abu Hammad $^{(22)}$ they found that $62.1 \%$ of the subjects in the posttest were able to mention the BF benefits to baby compared to $31.02 \%$ in the pretest and mothers' knowledge about the BF benefits to mothers has improved by around 34\% (pretest reading was $19.7 \%$ while posttest one was $53.6 \%$ ). indicating importance the interventions conducted to improve mothers' knowledge and practices towards the breast feeding.

The present study showed that the mean of total knowledge score was higher with significant difference $(\mathrm{p}<0.05)$ among working mothers, with increasing level of education of the mothers (table 4,7) this was consistent with Chaudhary et al ${ }^{(14)}$ who reported that working mothers and mothers with higher educational level were considered to have good knowledge while Mehta ${ }^{(15)}$ mentioned only educational level was statistically significant with regard knowledge about benefits of breast feeding.

Antenatal education and breastfeeding counseling seemed to be necessary for successful breastfeeding during the first 6 months of life. The study reflect the role of media and the health care unit in providing the correct knowledge since, mothers who received knowledge from Media \& combined source were with higher knowledge score than mothers who received from PHC workers (table $4,7)$ this may reflect the shortage of antenatal care services like counseling conducted from the public sector EDHS 2008 results indicate that health providers did not provide proper advice to pregnant women about breastfeeding $\left.^{(13}\right)$, also, El-Mougi et al ${ }^{(21)}$ conducted a study in Egypt to examine social and medical factors affecting breastfeeding, and found that antenatal care promoted the breastfeeding practices. In another study conducted in 
turkey revealed the proportion of exclusive breastfeeding was significantly high among participants who had antenatal education on $\mathrm{BF}^{(16)}$ In the current study the percentages of mothers who knew they shouldn't give artificial formula or fluids in first 6 months were $63 \%$ and $25 \%$ respectively (table 2) while in practice $31 \%$ of mothers gave artificial formula, $85 \%$ of mothers gave fluids (Table 5). On the other hand, nearly have of mothers $(49 \%)$ had an idea that EBF should for the first 6 months (table 2) the percent of our participants who practiced EBF was $12.5 \%$. Nearly half of them $(44 \%)$ at the age of 2 months others at age of 4 and 6 months $28 \%$ (table 5, 6). In Egypt, ${ }^{(23)}$ reported that although breastfeeding is initiated early for the majority of children, only $9.7 \%$ of the mothers remained exclusively breastfeeding for 6 months. Giving herbs was a common practice by $75 \%$ and artificial feeding by $14.8 \%$. Also, Abul-Fadl et al ${ }^{(27)}$ showed that two-thirds of the mothers in both UE and LE introduce herbal drinks or decoctions to their babies in the first 6 months. One-third of the mothers in both upper lower Ehypt and LE give infant milk formula before their babies get 6 months old. In Etiopia, Seid et al ${ }^{(28)}$ reported that $74.2 \%$ of infants received EBF which declined to $70.8 \%$ at age of 2-3 months and $47.5 \%$ at the age of $4-5$ months, while $45.3 \%$ of infants six months and older received EBF when asked retrospectively.

Our results showed significant association between EBF \& maternal age, age of child, male sex, early breastfeeding initiation after delivery, good knowledge and absence of breast feeding difficulties (table 6). After multivariate analysis by adjusted logistic regression, significant association only was found with male sex of child, early initiation of breast feeding and knowledge figer score (table 8). This was similar to Al Ghwass and Ahmed findings ${ }^{(23)}$ who concluded that significant association was found with maternal age, antenatal care, early breastfeeding initiation after birth, male infant, absence of breastfeeding difficulties, and no use of teats and pacifiers While, Seid et a ${ }^{(28)}$ found that maternal occupation, prenatal EBF plan, place of delivery, mode of delivery and receiving counseling/advice on infant feeding were significantly and independently associated with the EBF practice. Regarding breast feeding problems low percentages of mothers knew how to manage insufficient milk supply. About one third of mothers said that they should express the breast to manage breast engorgement while, most of mothers knew the causes of nipple soreness and laceration (table 3 ). In fact, about $5 \%$ of women actually had physiologic insufficient milk supply ${ }^{(19)}$. In practice $(14 \%)$ of mothers experienced insufficient milk supply for their babies (table 5) and this was lower than reported in others studies $(17,18,19)$ and this was the most common reason for stopping BF as reported by Al-Binali (19)

Conclusion and Recommendations: Although overwhelming scientific evidence supporting the integral role of $\mathrm{BF}$ in the survival, growth and development of a child as well as in the health of mother, there was a lack of knowledge and correct feeding practice of children regarding EBF. Working and educated mothers have good knowledge. Counseling for mothers on EBF needs to be improved and health care workers need to be better trained to provide 
counseling services during antenatal care visits. There is also a great need to create awareness of optimal breastfeeding practices and behavioral change among mothers and conduct an intervention to identify different factors affecting these feeding practices.

Acknowledgments

We would like to thank the mothers who agreed to participate to the study for their cooperation. Also, we are very thankful to the Readats of Bensaleh FHU for helping in data collection

\section{References}

1) Jones G, Steketee RW, Black RE, Bhutta ZA, Morris SS, Survival C: Child survival II How many child deaths can we prevent this year? Lancet 2003, 362:65-71.

2) Kramer MS, Kakuma R: The optimal duration of exclusive breastfeeding: a sysytematic review. Geneva: World Health Organization; 2002.

\section{3) World Health Organisation:}

Maternal,newborn,child and adolescent health: Breastfeeding; 2011. Available from: http://www.who.int.

\section{4) World Health Organization:}

Optimal Duration of Exclusive Breastfeeding: A Systematic Review. WHO/NHD/01.0. World Health Organization, Geneva, 2001

5) World Health Organization: Infant and young child feeding (IYCF) Model Chapter for textbooks for medical students and allied health professionals. Switzerland: World Health Organization; 2009

\section{6) Central Statistical Agency} [Ethiopia] and ORC Macro: Ethiopia Demographic and Health Survey (EDHS) 2005. Addis Ababa, Ethiopia and Calverton, Maryland, USA: Central Statistical Agency and ORC Macro; 2006.

7) Du Plessis D: Breastfeeding: mothers and health practitioners, in the context of private medical care in Gauteng. $J$ Interdiscipl Health Sci. 2009;14:1.

8) World Health Organization: The optimal duration of exclusive breastfeeding: report of an expert consultation. Geneva: World Health Organization, Department of nutrition for health and development and department of child and adolescent health and developmen; 2001.

9) World Health Organization: Global strategy for infant and young child feeding. The optimal duration of exclusive breastfeeding. Geneva: World Health Organization; 2001.

10) World Health Organization: Infant and young child feeding (IYCF). Model Chapter for textbooks for medical students and allied health professionals. Switzerland: World Health Organization; 2009.

\section{1) Fjeld E, Siziya $S$, Katepa-Bwalya} M, Kankasa C, Moland KM T: PROMISE-EBF Study Group: No sister, the breast alone is not enough for my baby' a qualitative assessment of potentials and barriers in the promotion of exclusive breastfeeding in southern Zambia. Int Breastfeed J. 2008;3:26.

12) Setegn T, Belachew T, Gerbaba M, Deribe M, Deribew A, Biadgilign 
$\mathrm{S}:$ Factors associated with exclusive breastfeeding practices among mothers in Goba district, south east Ethiopia: a cross-sectional study Int Breastfeeding J. 2012; 7:17.

13) El-Zanaty F, Way A: Feeding practices and micronutrient supplementation. In: Egypt Demographic and Health Survey 2008. Ministry of Health, El-Zanaty and Associates, and Macro International, Cairo, 2009, pp. 166-175.

14) Chaudhary RN, Shah T, Raja $S$ : Knowledge and practice of mothers regarding breast feeding: a hospital based study. BPKIHS Dharan. 2011 Sep -Dec 9 (3);194-200.

15) Mehta Y: A study on knowledge and practice of mothers regarding breast feeding in selected rural areas of Nepal. 2001.

16) Vehid HE, Haciu DV, Suphi GG, Bulut AA.:Study Of The Factors Affecting The Duration Of Exclusive Breastfeeding, Istanbul, Turkey Nobel Medicus Journal . 2009 Sep-Dec 5 ( 3);53-57.

17) Hector D, King L, Webb K: Interventions to encourage and support breastfeeding. NSW Public Health Bull. 2005; 16 (3-4):56-61. 18-Singh B. Knowledge, attitude and practice of breastfeeding - A case study.Eur J Sci Res. 2010; 40(3):404422.

19) Al-Binali: Breastfeeding knowledge, attitude and practice among school teachers in Abha female educational district, southwestern Saudi Arabia Int Breastfeed J.2012;7:10.
20) Ogbonna C, Daboer JC: Current knowledge and practice of exclusive breastfeeding among mothers in Jos,Nigeria. Niger J Med.2007 JulSep 16(3):256-60.

21) El-Mougi M, Mostafa S, Osman NH,Ahmed KA: Social and medical factors affecting duration of breastfeeding in Egypt. J Trop Pediatr 1981;27:5-11

22) Abu Hasan KM, Abu Hamad B:Effect of the Breast Feeding Promotion Program on Mothers' KAP: Al Quds University - School of Public Health - Gaza Ard El Insan Case. 23- Al Ghwass MME, Ahmed D: Prevalence and Predictors of 6-Month Exclusive Breastfeeding in a Rural Area in Egypt BREASTFEEDING MEDICINE Volume 6, Number 4, 2011 Mary Ann Liebert, Inc. DOI: $10.1089 / \mathrm{bfm} .2011 .0035$

24) Hornell A, Aarts C, Kylberg E, Hofvander Y, Gebre-Medhin $\mathrm{M}$ :Breastfeeding patterns in exclusively breastfed infants: A longitudinal prospective study in Uppsala, Sweden. Acta Paediatr 1999;88: 203-211.

25) World Health Organization: Complementary Feeding of Young Children in Developing Countries: A Review of Current Scientific Knowledge. WHO/NUT/98.1. World Health Organization,Geneva, 1998.

26) James DCS and Lessen R, Position of American Dietetic

Association: Promoting and supporting breastfeeding.

J Am Diet Assoc 2009, 109(11):19261942. 
27) Abul-Fadl AM, Shawky M, El-

Taweel A, Cadwell K, Turner-Maffei

C: Evaluation of Mothers' Knowledge, Attitudes, and Practice Towards the Ten Steps to Successful Breastfeeding in Egypt Breastfeed Med. 2012 Jun;7(3):173-8
28- Seid AM, Yesuf ME, Koye DN:

Prevalence of Exclusive Breastfeeding Practices and associated factors among mothers in Bahir Dar city, Northwest Ethiopia: a community based crosssectional study International Breastfeeding Journal 2013, 8:14 
Table1: Sociodemographic Characteristics of Interviewed mothers

\begin{tabular}{|l|c|c|}
\hline Variable & $\begin{array}{c}\text { Number } \\
\text { (400) }\end{array}$ & Percent \\
\hline Age groups(years): & 26 & \\
$\quad<20$ & 238 & 6.5 \\
$20-30$ & 136 & 39.5 \\
$\quad \geq 30$ & & \\
Mean age 28.06 \pm 5.8 & 392 & \\
\hline Marital status & 8 & 98.0 \\
$\quad$ Married & & 2.0 \\
WidowlDivorced & 42 & 10.5 \\
\hline Housewife Education & 24 & 6.0 \\
Illiterate & 106 & 26.5 \\
Read and write & 188 & 47.0 \\
Basic & 40 & 10.0 \\
Secondary & & \\
University & & \\
& 98 & 24.5 \\
\hline Occupation & 302 & 75.5 \\
Housewife & & \\
Employed & 66 & 16.5 \\
\hline Number of children & 90 & 22.5 \\
One & 150 & 37.5 \\
Two & 94 & 23.5 \\
Three & & \\
More than three & 194 & 48.5 \\
\hline Sex of last child & 206 & 51.5 \\
Male & & \\
Female & 98 & 24.5 \\
\hline Age of child & 104 & 26.0 \\
Two months & 198 & 49.5 \\
Four months & & \\
Six months & & \\
& & \\
\hline
\end{tabular}


Table 2: Distribution of Lactating mothers by general knowledge toward breastfeeding

\begin{tabular}{|l|l|c|}
\hline \multicolumn{1}{|c|}{ Variable } & $\mathbf{N}=\mathbf{4 0 0}$ & \% \\
\hline 1- Best time to initiate BF after delivery \\
\hline Within 1h * & 236 & 59.0 \\
\hline 2-3 hours & 102 & 25.5 \\
\hline 4 hours and above & 62 & 15.5 \\
\hline Times to BF day and night & & \\
\hline On demand* & 372 & 93.0 \\
\hline 10 times \& less & 28 & 7.0 \\
\hline Pattern of BF & 30 & 7.5 \\
\hline One side at time & 370 & 92.5 \\
\hline Both side at time & 252 & 63.0 \\
\hline Giving a baby Artificial Formula in her/his first six months \\
\hline No* & 148 & 37.0 \\
\hline Yes & 100 & 25.0 \\
\hline Giving a baby fluids in her/his first six months \\
\hline No* & 300 & 75.0 \\
\hline Yes & \multicolumn{1}{|l|}{} \\
\hline Duration of EBF & 62 & 15.5 \\
\hline 3 months \& less & 142 & 35.5 \\
\hline $4-5$ months & 196 & 49.0 \\
\hline 6 months * & 94 & 23.5 \\
\hline Cleaning breast before feeding \\
\hline Yes* & 306 & 76.5 \\
\hline No
\end{tabular}

*correct answer 
Table 3: Distribution of mothers by their knowledge about some breastfeeding problems

\begin{tabular}{|l|l|l|}
\hline \multirow{2}{*}{ Variable } & \multicolumn{2}{|c|}{$\mathrm{N}=400$} \\
\cline { 2 - 3 } & $\mathrm{N}$ & $\%$ \\
\hline Mothers' knowledge about the management of scanty milk \\
\hline Continue BF & 48 & 12.0 \\
\hline Give the baby AF by bottle* & 162 & 40.5 \\
\hline Increase the time of a single BF & 10 & 2.5 \\
\hline Increase BF frequency day and night & 44 & 11.0 \\
\hline Give the baby fluids (tea, herbals) by bottle* & 140 & 35.0 \\
\hline Mothers' knowledge about the management of breast engorgement \\
\hline Stop BF during engorgement* & 114 & 28.5 \\
\hline Increase times of BF & 44 & 11.0 \\
\hline Express the breast and give the milk to the baby & 146 & 36.5 \\
\hline Massage of the areola & 6 & 1.5 \\
\hline Put warm compresses on breast before BF & 6 & 7.0 \\
\hline Massage the whole breast* & 25 & 15.5 \\
\hline Mothers' knowledge about the causes of nipple soreness and laceration \\
\hline Poor positioning & 62 & 36.0 \\
\hline The baby suckles for long time & 144 & 33.5 \\
\hline The baby suckles the nipples and the areola* & 134 & 2.0 \\
\hline The baby suckles the nipples only & 8 & 28.5 \\
\hline
\end{tabular}

*wrong answer 
Table 4: Distribution of Interviewed women According to their Total Knowledge Score by Sociodemographic Data

\begin{tabular}{|c|c|c|c|c|}
\hline Variable & Mean of total & nowledge & Signific & ance* \\
\hline & Mean \pm SD & Range & $\mathrm{T} / \mathrm{F}^{*}$ & $\mathrm{P}$ value \\
\hline $\begin{array}{l}\text { Age groups(years): } \\
<20 \\
20-30 \\
30-\end{array}$ & $\begin{array}{r}10.5 \pm 2.3 \\
10.04 \pm 2.9 \\
10.5 \pm 3.11\end{array}$ & $\begin{array}{l}7-14 \\
5-19 \\
4-22\end{array}$ & 0.569 & 0.57 \\
\hline $\begin{array}{l}\text { Working Status } \\
\text { Not working } \\
\text { Working }\end{array}$ & $\begin{array}{l}9.6 \pm 2.6 \\
12.5 \pm 2.5\end{array}$ & $\begin{array}{l}4.46 \\
9.17\end{array}$ & 0.17 & 0.00 \\
\hline $\begin{array}{l}\text { Education } \\
\text { Illiterate \& Read and write } \\
\text { Basic } \\
\text { Secondary } \\
\text { University }\end{array}$ & $\begin{array}{l}9.45 \pm 3.6 \\
9.8 \pm 2.4 \\
10.35 \pm 2.76 \\
11.9 \pm 3.11\end{array}$ & $\begin{array}{l}4-22 \\
5-15 \\
5-19 \\
5-17\end{array}$ & 3.4 & 0.000 \\
\hline $\begin{array}{l}\text { Marital status } \\
\text { Married } \\
\text { Widow }\end{array}$ & $\begin{array}{l}10.22 \pm 2.9 \\
10.25 \pm 3.2 \\
\end{array}$ & $\begin{array}{l}4-22 \\
7-13 \\
\end{array}$ & 0.01 & 0.98 \\
\hline $\begin{array}{l}\text { Number of children } \\
1 \text { child } \\
2 \\
\geq 3\end{array}$ & $\begin{array}{l}10.48 \pm 2.2 \\
10.06 \pm 2.75 \\
10.2 \pm 3.17 \\
\end{array}$ & $\begin{array}{l}7-16 \\
5-15 \\
4-22 \\
\end{array}$ & 1.01 & 0.19 \\
\hline $\begin{array}{l}\text { Sex of child } \\
\text { Male } \\
\text { Female }\end{array}$ & $\begin{array}{l}10.11 \pm 2.89 \\
10.3 \pm 3.98\end{array}$ & $\begin{array}{l}4-19 \\
5-22\end{array}$ & 0.511 & 0.6 \\
\hline $\begin{array}{l}\text { Source of knowledge about BF } \\
\text { during ANC } \\
\text { TV } \\
\text { PHC health worker } \\
\text { Combined }\end{array}$ & $\begin{array}{r}11.7 \pm 3.5 \\
9.95 \pm 2.69 \\
10.8 \pm 2.95\end{array}$ & $\begin{array}{l}4-22 \\
5-18 \\
5-19\end{array}$ & 4.35 & 0.001 \\
\hline
\end{tabular}

Mean total score of all participants was $10.22 \pm 2.94$

T test was used for comparing two groups and ANOVA more than two groups F-test ANOVA 
Table 5: Distribution of mothers by their breastfeeding practices

\begin{tabular}{|c|c|c|}
\hline \multirow[t]{2}{*}{ Variable } & \multicolumn{2}{|c|}{$\mathrm{N}=400$} \\
\hline & $\mathrm{N}$ & $\%$ \\
\hline \multicolumn{3}{|c|}{ Time interval between birth and first breast feed: } \\
\hline Within $1 \mathrm{~h}$ & 174 & 43.5 \\
\hline $2-3 \mathrm{~h}$ & 124 & 31.0 \\
\hline$\geq 4 \mathrm{~h}$ & 102 & 25.5 \\
\hline \multicolumn{3}{|c|}{ Cleaning breast before feeding } \\
\hline No & 260 & 65.0 \\
\hline Yes & 22 & 5.5 \\
\hline Sometimes & 118 & 29.5 \\
\hline \multicolumn{3}{|l|}{ Feeding pattern } \\
\hline one side a time & 58 & 14.5 \\
\hline Both sides a time & 342 & 85.5 \\
\hline \multicolumn{3}{|c|}{ Giving artificial formula : } \\
\hline No & 276 & 69.0 \\
\hline Yes & 124 & 31.0 \\
\hline \multicolumn{3}{|c|}{ Giving fluids (herbals, tea, water, etc.) } \\
\hline No & 60 & 15.0 \\
\hline Yes & 340 & 85.0 \\
\hline \multicolumn{3}{|c|}{ If any complementary food is given beside BF: } \\
\hline No & 100 & 25.0 \\
\hline Yes & 300 & 75.0 \\
\hline \multicolumn{3}{|c|}{ Age at which to introduce fluids or complementary food: } \\
\hline $1-2$ months & 16 & 5.3 \\
\hline $3-4$ months & 208 & 69.3 \\
\hline $5-6$ months & 76 & 25.3 \\
\hline \multicolumn{3}{|c|}{ Times BF day and night: } \\
\hline Less than 10 times & 100 & 25 \\
\hline On demand & 300 & 75 \\
\hline \multicolumn{3}{|c|}{ Exclusive breast feeding practice } \\
\hline No & 350 & 87.5 \\
\hline Yes & 50 & 12.5 \\
\hline \multicolumn{3}{|c|}{ Experiencing difficulties BF a baby: } \\
\hline No difficulties & 316 & 79.0 \\
\hline Scanty milk & 58 & 14.0 \\
\hline Engorgement & 8 & 2.0 \\
\hline Inflammation & 12 & 3.0 \\
\hline Sore & 8 & 2.0 \\
\hline
\end{tabular}


Table 6: Association of Exclusive breast feeding and Sociodemographic characteristics and knowledge score

\begin{tabular}{|c|c|c|c|c|c|c|}
\hline & \multicolumn{4}{|c|}{ Exclusive BF Practices } & \multirow{2}{*}{\multicolumn{2}{|c|}{ Significance }} \\
\hline & \multicolumn{2}{|c|}{ Yes $=50$} & \multicolumn{2}{|c|}{$\mathrm{No}=350$} & & \\
\hline & $\mathrm{N}$ & $\%$ & $\mathrm{~N}$ & $\%$ & $\begin{array}{l}\text { Chi- } \\
\text { square }\end{array}$ & $\mathrm{P}$ \\
\hline $\begin{array}{l}\text { Age of mothers } \\
-<20 \text { years } \\
-20-30 \\
->30 \text { years }\end{array}$ & $\begin{array}{l}8 \\
32 \\
10\end{array}$ & $\begin{array}{l}16.0 \\
64 . \\
20.0\end{array}$ & $\begin{array}{l}18 \\
206 \\
126\end{array}$ & $\begin{array}{l}5.1 \\
58.9 \\
36.0\end{array}$ & 11.4 & 0.003 \\
\hline $\begin{array}{l}\text { Sex } \\
\text { - Female } \\
\text { - Male }\end{array}$ & $\begin{array}{l}16 \\
34 \\
\end{array}$ & $\begin{array}{l}32.0 \\
68.0\end{array}$ & $\begin{array}{l}158 \\
192 \\
\end{array}$ & $\begin{array}{l}45.1 \\
54.9\end{array}$ & 9.2 & 0.02 \\
\hline $\begin{array}{l}\text { Age of the child } \\
-2 \text { months } \\
-4 \text { months } \\
-6 \text { months }\end{array}$ & $\begin{array}{l}22 \\
14 \\
14\end{array}$ & $\begin{array}{l}44.0 \\
28.0 \\
28.0\end{array}$ & $\begin{array}{l}84 \\
90 \\
166\end{array}$ & $\begin{array}{l}24 \\
25.7 \\
56\end{array}$ & 10.1 & 0.006 \\
\hline $\begin{array}{l}\text { - Working status } \\
\text { - working } \\
\text { - Not-working }\end{array}$ & $\begin{array}{l}18 \\
32 \\
\end{array}$ & $\begin{array}{l}36.0 \\
64.0\end{array}$ & $\begin{array}{l}80 \\
270\end{array}$ & $\begin{array}{l}22.9 \\
77.1\end{array}$ & 4.08 & 0.053 \\
\hline $\begin{array}{l}\text { Education } \\
\text { - Illiterate \& read and write } \\
\text { \& basic } \\
\text { - Secondary High }\end{array}$ & $\begin{array}{l}22 \\
28\end{array}$ & $\begin{array}{l}44.0 \\
56.0\end{array}$ & $\begin{array}{l}150 \\
200\end{array}$ & $\begin{array}{l}42.9 \\
57.1\end{array}$ & 0.02 & 0.87 \\
\hline $\begin{array}{l}\text { Knowledge score } \\
\text { - Good knowledge } \\
\text { - Poor knowledge }\end{array}$ & $\begin{array}{l}44 \\
6\end{array}$ & $\begin{array}{l}88.0 \\
12.0\end{array}$ & $\begin{array}{l}180 \\
170 \\
\end{array}$ & $\begin{array}{l}51.4 \\
48.6 \\
\end{array}$ & 23.7 & 0.00 \\
\hline $\begin{array}{l}\text { Time of BF initiation } \\
- \text { Within the first hour } \\
-1-3 \text { hour } \\
->=4 \text { hour }\end{array}$ & $\begin{array}{l}44 \\
0 \\
6 \\
\end{array}$ & \begin{tabular}{|l}
88 \\
0 \\
22 \\
\end{tabular} & $\begin{array}{l}130 \\
124 \\
96\end{array}$ & $\begin{array}{l}37.1 \\
35.4 \\
27.5\end{array}$ & 47.8 & 0.00 \\
\hline $\begin{array}{l}\text { Facing problems during BF } \\
- \text { Yes } \\
\text { - No }\end{array}$ & $\begin{array}{l}0 \\
50\end{array}$ & $\begin{array}{l}0 \\
100.0\end{array}$ & $\begin{array}{l}84 \\
266\end{array}$ & $\begin{array}{l}24.0 \\
76.0\end{array}$ & 46 & 0.000 \\
\hline
\end{tabular}


Table 7: Multivariate logistic regression model showing Predictors of good knowledge

\begin{tabular}{|l|l|l|}
\hline Variables & $\begin{array}{l}\mathrm{P} \\
\text { value }\end{array}$ & OR( 95\% CI \\
\hline Age & 0.074 & $1.56(0.95-2.5)$ \\
\hline Occupation (working versus not working & 0.000 & $8.24(3.2-21.19)$ \\
\hline Sex (male versus female & 0.66 & $1.15(0.614-2.16)$ \\
\hline Order of the last child & 0.052 & $0.61(0.37-1.003)$ \\
\hline $\begin{array}{l}\text { Mother education ( high \& secondary education versus basic, } \\
\text { illiterate and read write }\end{array}$ & 0.865 & $0.946(0.49-1.79)$ \\
\hline $\begin{array}{l}\text { Source of knowledge(Media \& combined source versus } \\
\text { Raedat and PHC workers }\end{array}$ & 0.016 & $3.07(1.23-7.67)$ \\
\hline
\end{tabular}

Table 8: Multivariate logistic regression model showing Predictors of exclusive breast feeding

\begin{tabular}{|l|l|l|}
\hline Variables & $\begin{array}{l}\text { P } \\
\text { value }\end{array}$ & OR( 95\% CI \\
\hline Age( less than 30 versus > years & 0.366 & $1.98(0.45-8.7)$ \\
\hline Occupation (working versus not working & 0.37 & $1.4(0.65 .-3.2)$ \\
\hline Sex (male versus female & 0.003 & $3.02(1.45-6.3)$ \\
\hline Order of the last child & 0.42 & $0.62(0.19-1.98)$ \\
\hline $\begin{array}{l}\text { Early initiation of breast feeding( within } 1^{\text {st }} \text { hour versus/after } \\
1^{\text {st }} \text { hour }\end{array}$ & 0.000 & $13.2(5.19-33.47)$ \\
\hline $\begin{array}{l}\text { Mother education ( high \& secondary education versus basic, } \\
\text { illiterate and read write }\end{array}$ & 0.165 & $0.56(0.26-1.2)$ \\
\hline Knowledge score (good versus poor knowledge) & 0.000 & $7.9(2.9-21.3)$ \\
\hline
\end{tabular}




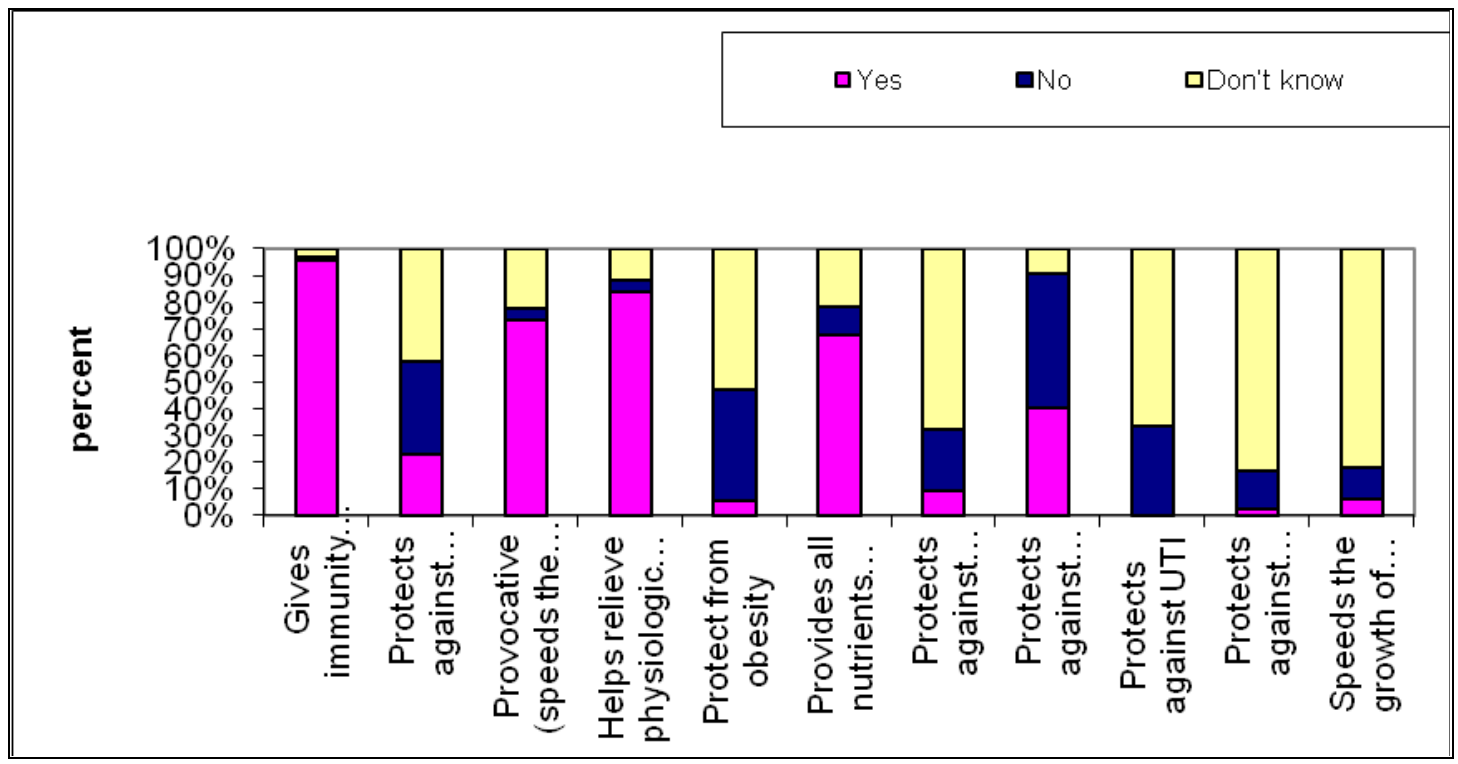

\section{Figure (1): Knowledge of benefits of BF to baby}

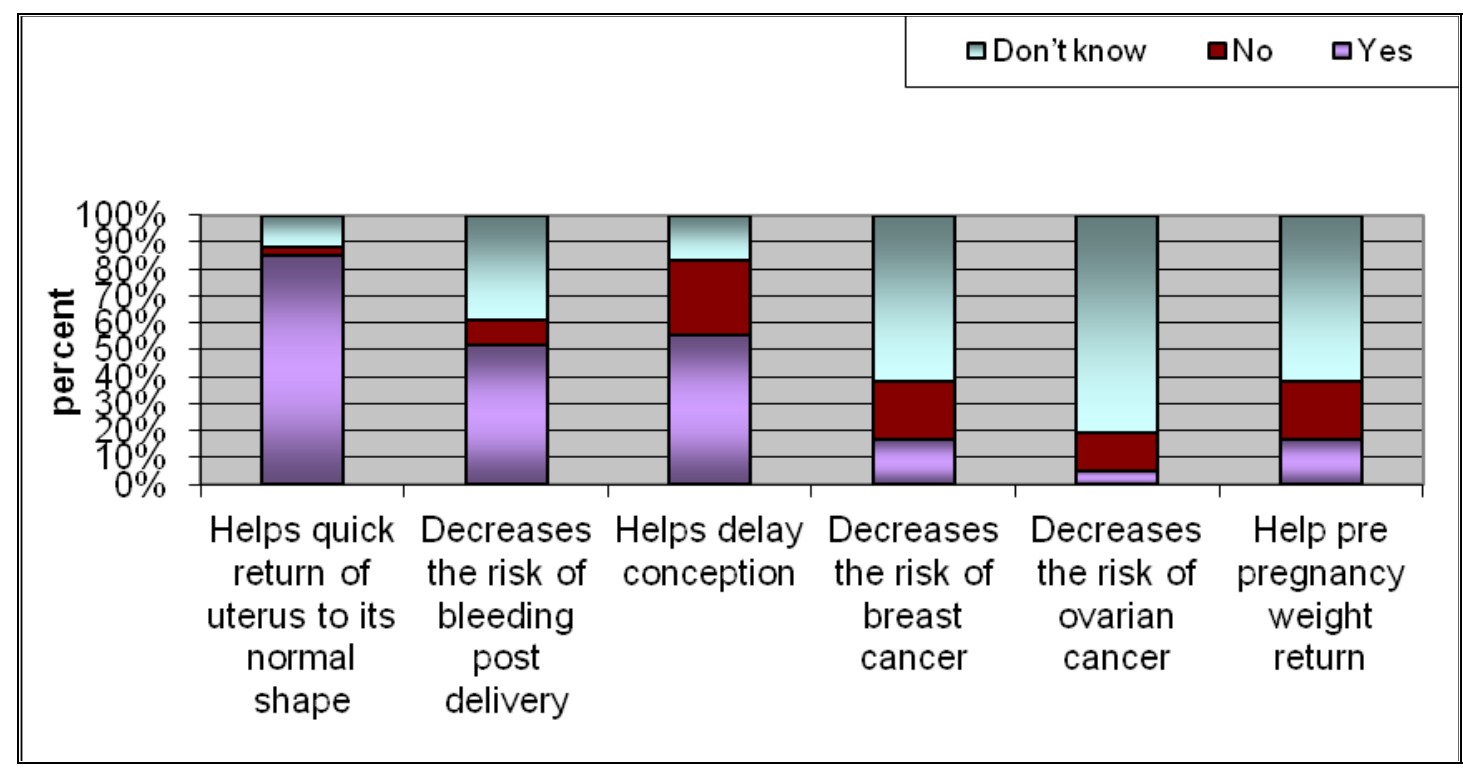

Figure (2): Knowledge of benefits of BF to mothers 